\title{
Behavioural Trend of Radial Stress Along a Radial Circular Cross Bore in Thick Walled Cylinders
}

\author{
P. K. NZIU* and L. M. MASU \\ Department of Mechanical Engineering, Vaal University of Technology, South Africa.
}

ORCIDs: 0000-0002-5899-0700 (PK Nziu), 0000-0002-8544-6321 (Prof. LM Masu)

\begin{abstract}
The behavioural trend of the magnitude of radial stress along the surface of a radial circular cross bore in thick walled cylinder was established in this work. This behavioural trend of radial stress along the cross bore surface was investigated on both small and large cross bore sizes in thick walled cylinders. The bore ratios for the small cross bore size were $0.1,0.3$ and 0.5 . Whereas, for large cross bore size the bore ratio was 0.7 and 1.0. On the other hand, the thickness ratios for the cylinders were $1.4,1.5,1.75,2.0,2.25,2.5$ and 3.0. With exception of the smallest cross bore size with bore ratio of 0.1 , the magnitude of the radial stress along the surface of the cross bore had insignificant variation from the gauge pressure.
\end{abstract}

Keywords: Thick cylinders, radial cross bore, radial stress, behavioural trend

\section{INTRODUCTION}

Radial stress is one of the principal stresses taken into consideration during the design of pressure vessels (Harvey, 1985). It is used in the computation of safe working elastic stresses which determine the capacity of pressure that causes yielding of the pressure vessel (Hearn, 1999).

In case of plain cylinders, radial stress has critical magnitude at the inner surface of the vessel. This critical magnitude is usually equal to the internal pressure sometimes referred to as gauge pressure (Harvey, 1985). Previous authors (Geerden, 1972; Ford and Alexander, 1977; Masu, 1989; Nziu and Masu, 2019) applied the aforementioned phenomenon whenever developing analytical solutions for cross bored thick-walled cylinders. These studies assumed that the magnitude of radial stress is constant along the surface of the cross bore (similar to the main bore), with a magnitude equal to the internal pressure. Though, a recent study by Nziu and Masu (2019b) reported that the critical magnitude of working stress in a cross bored cylinder does not necessarily occur at the intersection of the cross bore, but some distance away from the intersection. Thus, it is desirable to establish the behavioural trend of the radial stress along the surface of the cross bore and ascertain its effects on working stresses in cross bored thick cylinders.

Therefore, this study seeks to establish the behavioural trend of radial stresses along the surface of radial circular cross bores using Finite Element Analysis (FEA) for both small and large cross bores.

\section{METHODOLOGY}

\section{Cross bore configuration}

Figure 1 shows a configuration of the radial circular cross bore studied in this work.

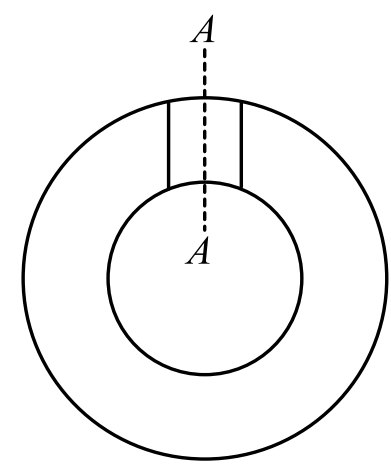

Figure 1: Configuration of the radial cross bore

\section{Studied Cases}

The behavioural trend of radial stress along the cross bore surface was investigated on both small and large cross bore sizes in thick walled cylinders. The bore ratios for the small cross bore size were $0.1,0.3$ and 0.5 . Whereas, for large cross bore size the bore ratio was 0.7 and 1.0. On the other hand, the thickness ratios for the cylinders were 1.4, 1.5, 1.75, 2.0, 2.25, 2.5 and 3.0.

\section{Finite Element Analysis}

A total of 35 FEA models were created and analysed using a commercial engineering software known as Abaqus version 16. Since the configuration of radial circular cross bore along the transverse edge is symmetrical (see figure 1), only an eighth of the structure was used for this analysis.

Asymmetrical boundary conditions were applied at each cut section of the model structure to enforce the exact symmetrical behaviour and deter any unlimited movement of the model. Further, displacement along the $\mathrm{Z}$ axis at the far end of the cylinder was also restrained as in the case of thick-walled closed cylinders to induce axial stresses. Subsequently, the vessel was then load with internal pressure at both the main bore and the cross bore. A detailed finite element modelling 
International Journal of Engineering Research and Technology. ISSN 0974-3154, Volume 13, Number 9 (2020), pp. 2343-2346

(C) International Research Publication House. https://dx.doi.org/10.37624/IJERT/13.9.2020.2343-2346

procedure followed in this article is found in Nziu (2018) doctoral thesis work.

\section{RESULTS AND DISCUSSION}

In this section, the generated FEA radial stress results were presented and compared with that given by the analytical

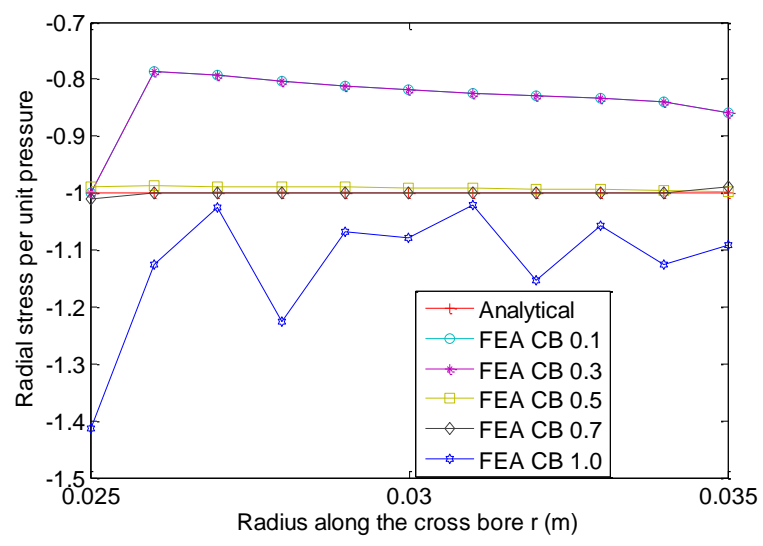

Figure 2 : Radial stress for $\mathrm{K}=1.4$

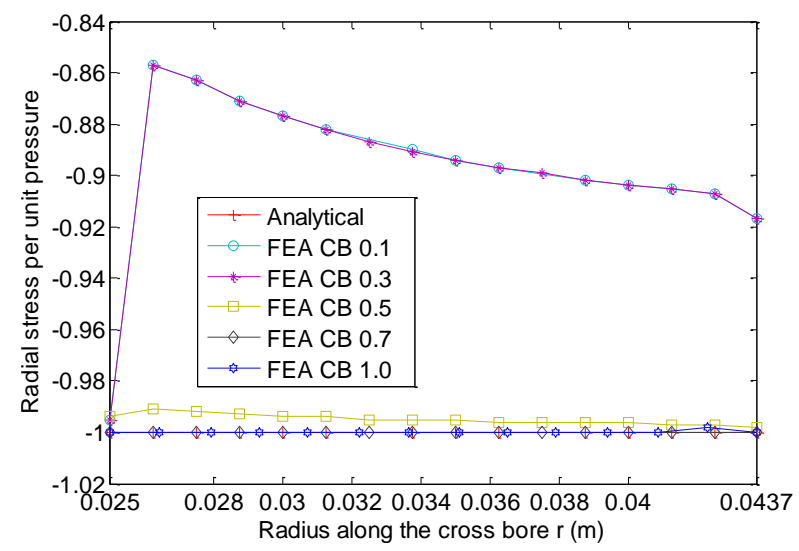

Figure 4: Radial stress for $K=1.75$

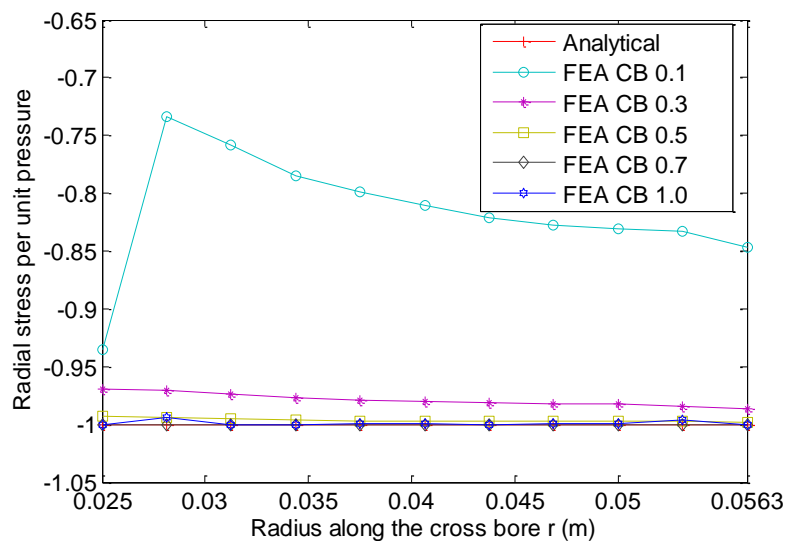

Figure 6 : Radial stress for $\mathrm{K}=2.25$ method as follows:

\section{Radial stress component in the direction of the main} cylinder

Graphs illustrating the radial stress along the cross bore for each thickness ratio are presented as follows in figures $2-8$ for $\mathrm{K}=1.4,1.5,1.75,2.0,2.25,2.5$ and 3.0.

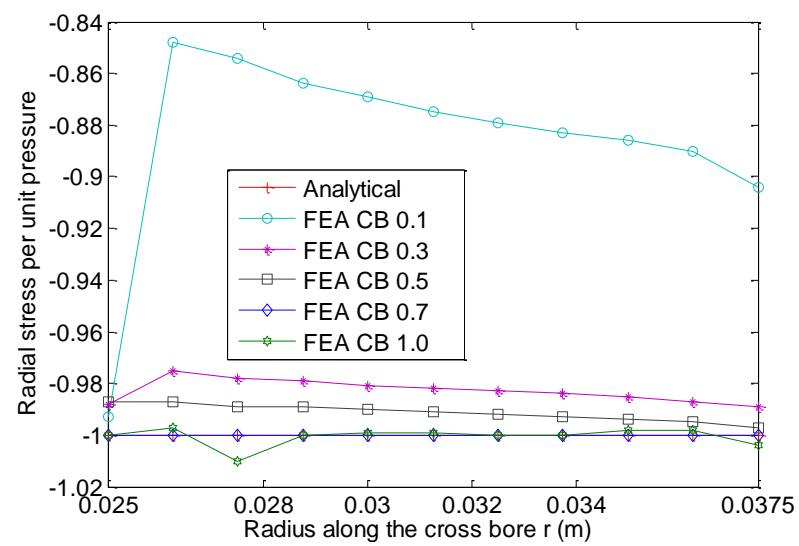

Figure 3: Radial stress for $\mathrm{K}=1.5$

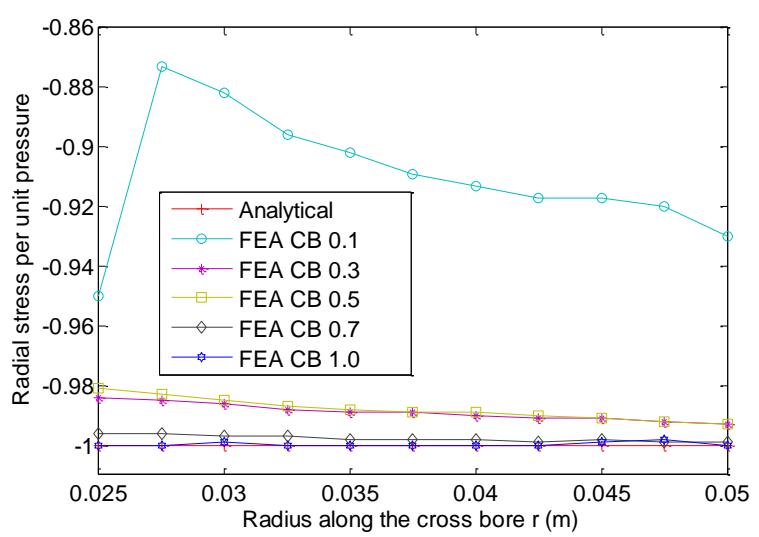

Figure 5: Radial stress for $\mathrm{K}=2.0$

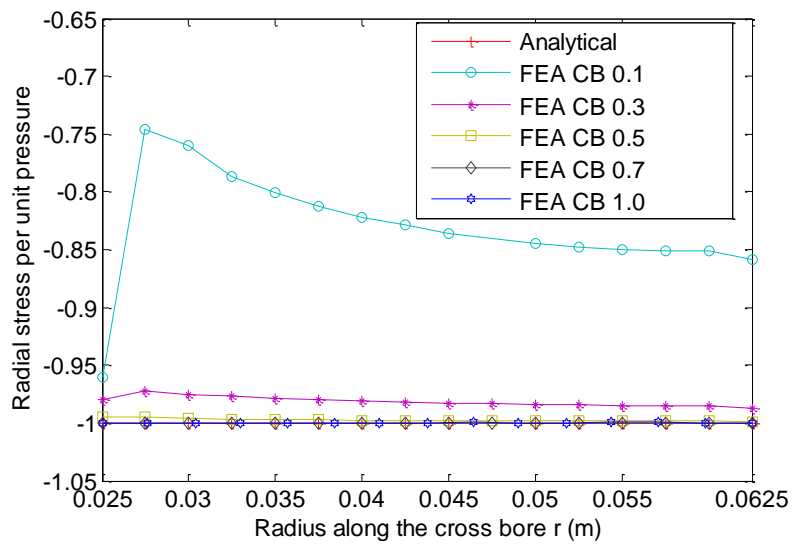

Figure 7: Radial stress for $\mathrm{K}=2.5$ 


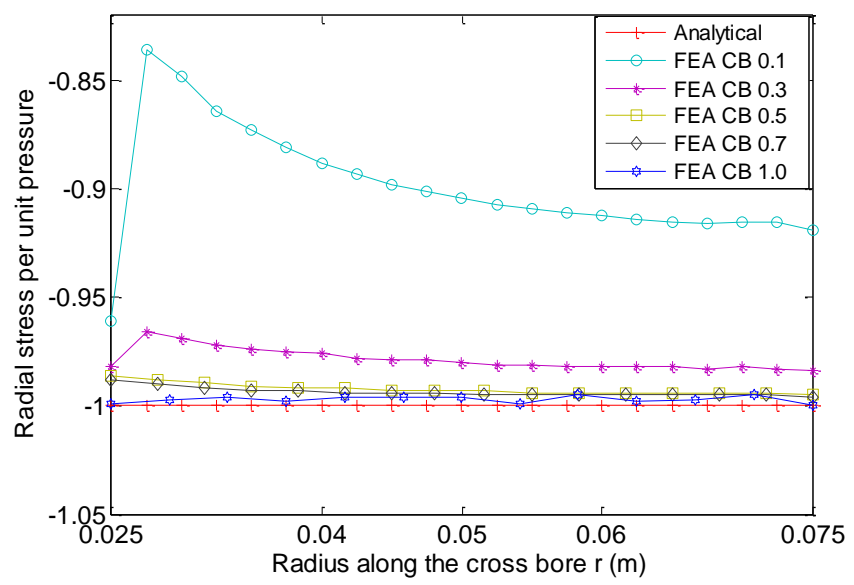

Figure 8: Radial stress for $\mathrm{K}=3.0$

Figures 2 - 8: Radial stress distribution per unit pressure along a circular cross bore, for various thickness ratios and cross bore sizes.

During the development of the analytical solution, it was assumed that the radial stress along the surface of the cross bore was constant. The magnitude of the constant radial stress per unit pressure was taken as -1 (compressive), which was equal and opposite to the gauge pressure. This assumption was in line with other previous studies by Geerden (1972) and Ford and Alexander (1977).

Interestingly, the FEA data presented in this work, compared favourably with the corresponding analytical ones, when the cross bore size ratios were $0.3,0.5,0.7$ and 1.0. The radial stress distribution graphs showing the concurrence between the two methods is illustrated in Figures 2-8. However, it was noted that the radial stress distribution curve given by the largest cross bore size on $\mathrm{K}=1.4$ was considerably different. The appearance of the radial stress curve was close to a sinusoidal wave form but with sharp edges as shown in Figure 2. Moreover, the radial stress per unit pressure at the intersection was slightly lower at -1.414 for the same thickness ratio. Because, structural stiffness of the cylinder is affected by the cross bore size, large cross bores sizes cause the structural stiffness of the vessel to reduce leading to higher stresses.

On each thickness ratio, a similar stress distribution pattern as shown in Figures 2 to 8, was observed on the smallest cross bore size ratio of 0.1 . At the intersection, the radial stress per unit pressure given by the smallest cross bore size was -1 , after which it reduced sharply to a minima, before gradually increasing towards the outside surface of the cylinder. The magnitude of the lowest minima was at 0.734 in $\mathrm{K}=2.25$. Usually, the solution of finite element analysis takes place at the gauss points and then extrapolated to the nodes at the surface. Probably this aforesaid occurrence might be associated with the stress extrapolation during the FEA analysis stage in Abaqus software, among other factors. The extrapolation process might lead to the prediction of inaccurate stresses at the surface of the cross bore. Further verification needs to be done to ascertain the accuracy of these results. It is, therefore, recommended that a software package, such as Boundary Integral Element, which is more suitable in analysing stresses at the surface of the elements, should be used. It is worth noting that the total radial stress along the cross bore is the summation of the radial stress in the main cylinder with a bore and the corresponding axial stress produced by the pressurised cross bore. However, since the cross bore is open ended, the corresponding axial stress is zero. Hence the total radial stress is equal to the gauge pressure. This observation agrees with the phenomenon that pressure is equal in all direction.

\section{CONCLUSION}

With exception of the smallest cross bore size with bore ratio of 0.1 , the magnitude of the radial stress along the surface of the cross bore had insignificant variation from the gauge pressure.

\section{ACKNOWLEDGEMENTS}

This work was supported by the Department of Mechanical Engineering, Vaal University of Technology, South Africa.

\section{REFERENCES}

[1] Ford, H. and Alexander, J. (1977), "Advanced mechanics of materials", John wiley and sons inc., Canada, second edition.

[2] Harvey, J. F. (1985), "Theory and design of pressure vessels", Van Nostrand Reinhold Company Inc., ISB No. 0-442-23248-9.

[3] Hearn, E. J. (1999), "Mechanics of materials 2", Butterworth-Heinemann, Great Britain, ISBN 0-7506 3266-6, Third edition.

[4] Masu, L. M. (1989), "The effect of cross bore geometry on the strength of pressure vessels", $P h D$ thesis, University of leeds.

[5] Nziu, P. K. (2018), “Optimal geometric configuration 
International Journal of Engineering Research and Technology. ISSN 0974-3154, Volume 13, Number 9 (2020), pp. 2343-2346

(C) International Research Publication House. https://dx.doi.org/10.37624/IJERT/13.9.2020.2343-2346

of a cross bore in high pressure vessels", Doctorate thesis, Vaal University of Technology

[6] Nziu, P.K. and Masu, L. M. (2019a) Formulae to predict hoop stresses along the transverse XY plane of a small radial circular cross bore in thick cylinders, International journal of mechanical \& production engineering research and development" ISSN 22496890/2249-8001, Vol.9, issue 6, pp 707-724, doi: 10.24247/ijmperddec201960

[7] Nziu, P.K. and Masu, L. M. (2019b) "Formulae for predicting stress concentration factors in flat plates and cylindrical pressure vessels with holes: A review", International journal of mechanical and production engineering research and development, ISSN 22496890, 2019, Vol. 9, issue 5, pp. 753-770, doi: 10.24247/ ijmperdoct 201967 